\title{
A triage approach to improve the relevance of marine ecosystem services assessments
}

\author{
Linwood Pendleton ${ }^{1,2, *}$, Rémi Mongruel ${ }^{3}$, Nicola Beaumont ${ }^{4}$, Tara Hooper ${ }^{4}$, \\ Mahé Charles ${ }^{5}$
}

${ }^{1}$ UMR-AMURE, Université de Bretagne Occidentale, 12 rue de Kergoat - CS 93837, 29238 Brest Cedex 3, France

${ }^{2}$ Nicholas Institute for Environmental Policy Solutions, 2101 Campus Drive, Durham, NC 27708, USA

${ }^{3}$ UMR-AMURE, Marine Economics Unit, Ifremer Centre Bretagne, ZI de la Pointe du Diable - CS 10070, 29280 Plouzané, France

${ }^{4}$ Plymouth Marine Laboratory, Prospect Place, Plymouth, Devon PL1 3DH, UK

${ }^{5}$ French Marine Protected Area Agency/Agence des aires marines protégées, 16 quai de la Douane - CS 42932, 29229 Brest Cedex 2, France

\begin{abstract}
Ecosystem services assessments are increasingly being used to inform marine policy and planning. These assessments involve significant time, effort, and expertise. It is important at the outset to determine which of many ecosystem services should be quantified and which measures of ecological output, economic impact, or value should be assessed. Furthermore, the literature shows that in practice such assessments are unevenly applied and rarely used effectively in decision-making processes. We develop a structured decision-making approach, called a triage, to assess what types of ecosystem services should be assessed to improve the uptake and usefulness of such information in marine planning. Two case studies, in France and the United Kingdom, provide examples of the application of the triage approach.
\end{abstract}

KEY WORDS: Ecosystem services $\cdot$ Assessment $\cdot$ Marine planning $\cdot$ Marine protection

\section{INTRODUCTION}

Increasingly, a marine ecosystem services (MES) approach is being used to inform marine policy and planning (Börger et al. 2014). Beyond a basic framework for thinking about the relationship between ecological conditions and humans, the ecosystem services (ES) approach often involves the direct quantification of ES production, consumption, and value (MEA 2005, TEEB 2010). There are no clear guidelines, however, about which of the many possible ES could and should be quantified or how a quantitative assessment of them should inform policy. As a result, MES approaches have been applied unevenly by marine planners (Egoh et al. 2007). The effective use of ecosystem services assessment (ESA) and valuation for decision-making remains rare (Laurans et

\footnotetext{
${ }^{*}$ Corresponding author: linwood.pendleton@univ-brest.fr
}

al. 2013), especially for marine management (Marcone \& Mongruel 2014).

Recent experience shows that ESAs are more likely to be used for management purposes when decisionmakers or stakeholders are involved in the assessment process. A more transparent and strategic approach could help analysts and scientists working on ES better match research to policy (Honey-Rosés \& Pendleton 2013). Only a few studies have explored this type of approach to ESA. Ruckelshaus et al. (in press) describe an ESA approach that uses simple ecological production function models and a variety of metrics including monetary values, and links changes in ES to changes in livelihoods, health, culture and other dimensions of human well-being. The authors also describe an ESA that includes an iterative science-policy process involving local stake-

() The authors 2015. Open Access under Creative Commons by Attribution Licence. Use, distribution and reproduction are unrestricted. Authors and original publication must be credited. 
holders. Lopes \& Videira (2013) propose a model for ESA that involves a 3-stage process defining and valuing ES: 'set the scene', 'deepen understanding', and 'articulate values'.

We build upon the literature to define a procedure that will tailor marine ecosystem services assessments (MESA) to the needs of stakeholders and decision-makers. We use 2 case studies to demonstrate how a triage process can help to narrow and define the aim, scope, methods and tools of a MESA so that it will be meaningful (interpretable), useful (in relation to management concerns, needs and projects), and feasible (according to the available knowledge and means).

\section{METHODS}

The assessment and valuation of MES can promote a better understanding of the ES provided to people by the marine environment and how these services might change under different types of marine management. It is important to decide, at an early stage, whether a MESA will aid policy-making, especially since the application of ESA tools is time consuming and costly (Bagstad et al. 2013). We develop a structured decision-making (SDM) approach we call the triage to provide a transparent procedure for delimiting the scope of a potential MESA, using a step-wise process to determine the relevance of the MESA for a particular policy decision, decide which MES to quantify, and how to quantify and measure the selected MES.

Following Lopes \& Videira (2013), we identify 3 broadly defined stages that characterize the triage process (Fig. 1). The first stage in the triage process is to transparently determine why an assessment is being undertaken and what its general scope is. Surprisingly, this first stage is often overlooked (Laurans et al. 2013, Marcone \& Mongruel 2014). In this stage, it is important to determine whether a proposed policy process involves trade-offs that include ES, whether decision-makers are willing to consider ES information, and what are the geographic and temporal scales of the proposed management realm. The second stage further refines the scope of the study by identifying the specific types of ES that need to be quantified to best inform policies. This stage also must consider whether an assessment is feasible, and how useful such an assessment would be. Finally, in the third stage, one decides exactly how to quantify ES (e.g. measures of ecological output, economic impact, economic value, etc.).

\section{Stage 1: Need for a marine ecosystem services assessment (MESA) and general scoping}

This first stage examines why an assessment is being undertaken and what its general scope should

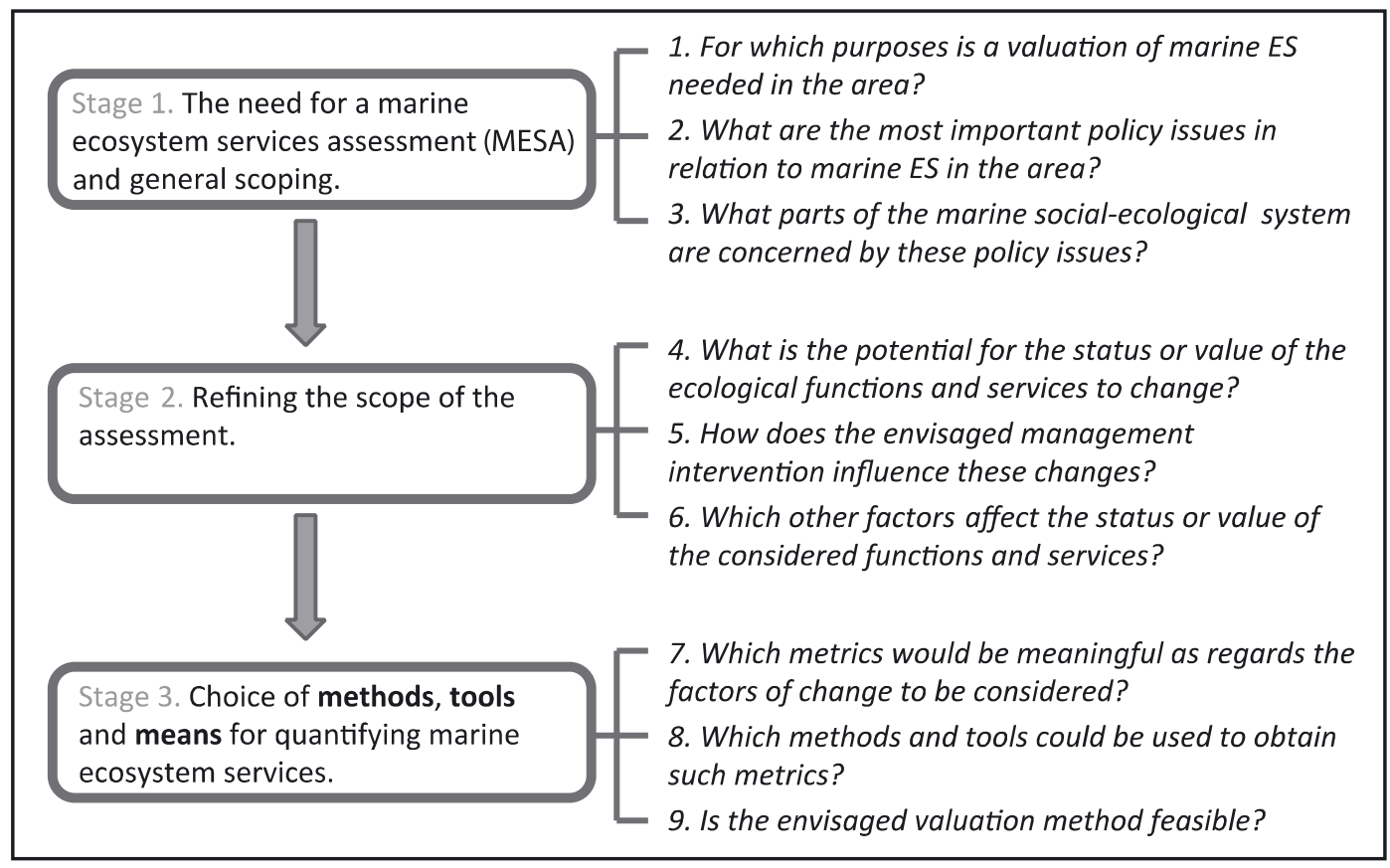

Fig. 1. The 3 stages of the triage approach to marine ecosystem services assessment (MESA) 
be, including site selection, scales, the need for trade-offs, whether managers are interested in ES data, etc. We use a series of questions to help technical experts and stakeholders agree upon the aim of the assessment, the issues at stake and the temporal and spatial scope of an assessment.

(1) For what purposes is a valuation of MES needed in the area? This first question relates to the operational needs of the stakeholders and decisionmakers who are considering a MESA. Following the classification by Laurans et al. (2013), 3 categories of uses of a MESA are considered: (1) informative uses, such as knowledge improvement, knowledge integration, initial diagnosis of key marine issues in the area, and raising awareness; (2) decisive uses, such as anticipating future changes, facilitating trade-offs, and comparison of management options; and (3) technical uses, i.e. mainly the design of management options (Table 1).

(2) What are the most important policy choices that affect MES in the area? The policy may be linked to the impacts of particular activities, the claims of certain stakeholders or a possible change in collective rules. It is useful to be precise when defining the policy issue, and to establish a ranking when several policy issues are of interest. For instance, stakeholders can be asked to assign a score (high, moderate, low) to indicate the relevance of different policy issues and then meet to deliberate and select the most relevant issues.

(3) What parts of the marine social-ecological system could be affected by these policy choices? It is important to specify the list of the ecosystem components, functions and ES that relate to the defined policy issues, as well as to identify the stakeholders and institutions whose actions are affected by these policy issues.

\section{Stage 2: Refining the scope of the assessment}

Not all policy decisions are made on the basis of how they affect ES. Similarly, not all ES are affected by a particular policy action. The key to making MESAs effective and useful is to try to ensure that the scope of the assessment is appropriate for stakeholder and decision-maker needs. To implement Stage 2 of our triage, we ask 3 key questions that help decision-makers, stakeholders, and scientists to refine their choice of which ES to assess and to what policy end.

(1) What is the potential for the status or value of ecological functions and services to change? Simply
Table 1. Results of ranking potential uses of marine ecosystem services assessment (MESA) at the Iroise Marine Natural Park (PNMI) and North Devon's Biosphere Reserve (NDBR). Scores were assigned as follows: $1=$ main purpose; $2=$ secondary purpose; $3=$ tertiary purpose. Only reasons meriting a 1, 2 or 3 are scored

\begin{tabular}{|lcc|}
\hline Category & PNMI & NDBR \\
Purpose & & \\
\hline $\begin{array}{l}\text { Informative use } \\
\text { Improve knowledge }\end{array}$ & $\mathbf{2}$ & $\mathbf{3}$ \\
$\begin{array}{l}\text { Integrate knowledge } \\
\text { Initial diagnosis of key marine issues }\end{array}$ & $\mathbf{2}$ & \\
Raising awareness & & $\mathbf{3}$ \\
$\begin{array}{l}\text { Decisive use } \\
\text { Anticipating future changes } \\
\text { Facilitate comparison of tradeoffs } \\
\text { Compare management options }\end{array}$ & $\mathbf{3}$ & \\
$\begin{array}{l}\text { Increasing wellbeing } \\
\text { Technical use }\end{array}$ & $\mathbf{1}$ & \\
Design management options & & $\mathbf{1}$ \\
\hline
\end{tabular}

put, if an ES is not likely to change in the future, then a formal assessment of this service will be of limited use. While this should be obvious, it is common to assess the value of things like cliffs or seascapes that are not likely to change. It also is the case that some ES are much more likely to change in the absence of a policy action than other services. If a formal valuation or monetisation is considered, the analyst should also consider the potential magnitude of change in value. A highly valuable ES may change only slightly in ecological terms, but its value could change substantially - either because the value per unit is very high or because social preferences for the ES change (see Tallis et al. 2012). The opposite also is true. If the change in quantity or value of the ES due to an action will be very small (for example carbon sequestration on a local scale) then there is very limited justification for an assessment.

(2) How does the envisaged management intervention influence these changes? If the specific management action is unlikely to have a significant influence on the provision and value of a MES, then a MESA will have little relevance for local policy. For example, if an issue or area is primarily governed by EU initiatives it may be more useful to conduct MESAs that focus on local policy actions (or policy actions at a scale appropriate to the decision needs).

(3) What other factors affect the status or value of the functions and services under consideration? The influence of wider social, economic, environmental and political issues, particularly those beyond the control of local management structures (such as cli- 
Table 2. Criteria for scoring marine environmental services (ES) in the triage process

\begin{tabular}{|llll|}
\hline $\begin{array}{l}\text { Usefulness of } \\
\text { ES assessment }\end{array}$ & $\begin{array}{l}\text { Potential for ES } \\
\text { value to change }\end{array}$ & Influence of management on ES & Other factors affecting ES \\
\hline High & $\begin{array}{l}\text { Service is sensitive to } \\
\text { impacts and value change } \\
\text { will be large }\end{array}$ & $\begin{array}{l}\text { Management will have a large influence on } \\
\text { value, a strong probability of coming into } \\
\text { effect and is locally driven }\end{array}$ & $\begin{array}{l}\text { Local environmental factors } \\
\text { have the strongest influence } \\
\text { on value }\end{array}$ \\
& $\begin{array}{l}\text { Service is sensitive to } \\
\text { impacts and value change } \\
\text { will be small }\end{array}$ & $\begin{array}{l}\text { Management will have a large influence on } \\
\text { value and at least a reasonable probability } \\
\text { of coming into effect, but is not locally driven }\end{array}$ & $\begin{array}{l}\text { Other factors (social, } \\
\text { economic, political, global } \\
\text { environmental change) } \\
\text { have a similar influence on } \\
\text { value to that of local } \\
\text { environmental factors }\end{array}$ \\
& $\begin{array}{l}\text { Service is robust and value } \\
\text { change will be large }\end{array}$ & $\begin{array}{l}\text { Management will have a moderate influence } \\
\text { on value, at least a reasonable probability of } \\
\text { coming into effect and is locally driven }\end{array}$ & $\begin{array}{l}\text { Other factors have the } \\
\text { strongest influence on value }\end{array}$ \\
& $\begin{array}{l}\text { Service is robust and value } \\
\text { change will be small }\end{array}$ & $\begin{array}{l}\text { Management will have a small influence on } \\
\text { value and/or a low probability of coming into } \\
\text { effect }\end{array}$ &
\end{tabular}

mate change or national/transnational policies) may affect the usefulness of a MESA. Where these wider issues have a relatively larger impact on the provision of MES than the proposed policy-driven change, a change in ES provision or in value expected from local management action is less likely to be realised.

These 3 questions can be applied to evaluate proposals to assess particular policies or, if it has already been decided to assess the policy (e.g. if laws or regulations require it), the selection of ES to assess. The usefulness of assessing each policy or ES can be scored (high, moderate, low) in response to these questions (Table 2). The scores from each question can be examined individually or combined to create a summary score. Stakeholders, decision-makers, and specialist experts can take part in scoring. Alternatively, if many complicated options exist, scores can be assigned by small groups of experts to initially narrow down the options, and a more collaborative approach can be taken to score the alternatives on the shortlist.

\section{Stage 3: Methods and tools for quantifying marine ecosystem services (MES)}

Once ES have been chosen, the final step is to decide how to measure these services and specify the metrics to be used for their assessment. This process is a normal part of any assessment. Nevertheless, we found 3 recurring questions that helped guide the process of choice of methods and metrics:

(1) Which metrics would best inform the policy decision? Depending on the factors of change, different types of metrics could be meaningful: changes related to ecological status could captured using biophysical metrics, and changes affecting human activities may be expressed in terms of monetary values or jobs; changes related to trade-offs may also require measures to assess social perceptions, related to MES and changes in MES. In most cases, a mix of indicators from different categories may well be appropriate.

(2) Which methods and tools could be used to obtain such metrics? Once the metrics and indicators for assessing ES have been chosen, quantification methods should be selected. The method chosen will depend on the aim of the assessment, the stage of the management process it is intended to support, and the degree to which stakeholders and decisionmakers trust the results of different methodologies. Broad objectives associated with early management stages, like initial diagnosis and policy design, may require broad-scope assessment methods, while more operational objectives like the comparison of management options could require more focused methods. The products of methodologies for quantifying MES that use ecological, economic and social indicators can be values for single indicators, multicriteria assessments or integrated assessments.

(3). What resources are required to implement the preferred methods and tools? Finally, the effort and cost requirements for assessing different ES can vary considerably depending on the methods proposed, and must be explicitly considered. Where resources for primary data collection are limited, the availability of secondary data (both ecological and socioeconomic) will also have a strong influence on the scope of a MES assessment. 


\section{APPLICATIONS}

We applied the triage approach to sites in the UK and France as part of the European-funded project Valuing Ecosystem Services in the Western Channel (VALMER), which investigates how MESA can support effective marine planning and management (Fig. 2); 2 case studies from that project are presented here: (1) the North Devon's Biosphere Reserve (NDBR), and (2) the Iroise Marine Natural Park (Parc Naturel Marin d'Iroise, PNMI).

\section{North Devon's Biosphere Reserve (NDBR)}

Braunton Burrows Biosphere Reserve, locally known as the NDBR, was designated under the UNESCO Man and the Biosphere Programme, the purpose of which is to promote community efforts in sustainable development. It is managed by a stakeholder partnership that includes statutory agencies, local councils, local and national conservation organisations, educational institutions, recreation and tourism groups, and representatives from fishing and farming groups. The NDBR covers $>3300 \mathrm{~km}^{2}$, half of which is coastal and marine habitat, including an extensive dune system that comprises the core of the reserve, as well as rocky foreshore, estuarine saltmarsh, and mud and sand flats. Tourism is a very important source of income for the local community, and fishing contributes to both the economy and the cultural heritage of the area.

This site was selected for assessment as it provides a wide variety of ES, but increasingly choices and trade-offs relating to their provision are having to be made. In addition, as it is already designated as a biosphere reserve, the site has well-established stakeholder groups, which were receptive to the ES approach. Finally, the coastal area had good data available.

\section{Stage 1}

A suite of management objectives has been defined (NDBR 2008, 2011). The management partnership must also respond to local and national
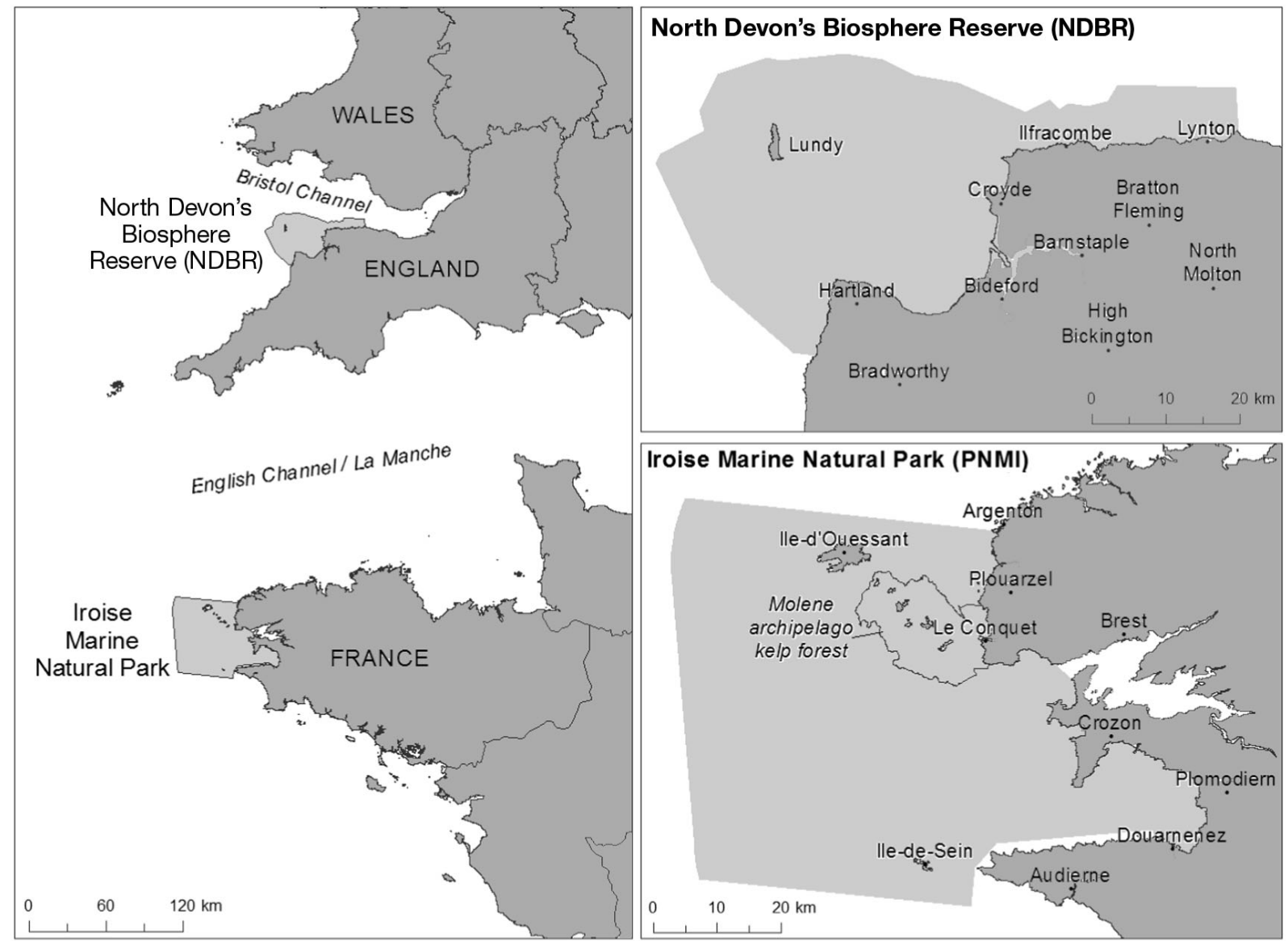

Fig. 2. Case study sites for application of the triage approach to marine ecosystem services assessment (MESA) 
Table 3. Scores assigned by experts and stakeholders for ecosystem services (ES) in North Devon's Biosphere Reserve (NDBR). See Table 2 for criteria for scoring

\begin{tabular}{|lccccccc} 
& \multicolumn{2}{c}{$\begin{array}{c}\text { Potential for ES value } \\
\text { to change }\end{array}$} & \multicolumn{2}{c}{ Influence of management } & \multicolumn{2}{c}{ Other factors } \\
& Experts & Stakeholders & Experts & Stakeholders & Experts & Stakeholders \\
\hline Carbon storage & Moderate & Moderate & Moderate & High & Moderate & Low \\
Waste remediation & Low & Moderate & Low & Moderate & Moderate & Moderate \\
$\begin{array}{l}\text { Benthic nursery habitat (linked } \\
\text { to fisheries provision) }\end{array}$ & High & High & High & High & Moderate & Moderate \\
$\begin{array}{l}\text { Recreational bird watching } \\
\text { Visual amenity }\end{array}$ & Low & Low & Moderate & High & Low & Moderate \\
& High & High & Moderate & Moderate & High & Low \\
\hline
\end{tabular}

initiatives including fisheries and habitat management, the potential development of renewable energy installations, and a possible increase in aggregate extraction. The management partnership decided to pursue a MESA for 2 primary purposes (1) to improve knowledge and raise awareness of the MES provided by the NDBR (informative uses) and (2) to collect evidence to support local management actions and to inform consultations where decisions will be taken at a national scale (decisive uses).

Following extensive consultations, both formal and informal, with selected stakeholders and members of the public, the key policy issues (and their related ecological and social components) were identified as:

(1) Changes in carbon storage as a result of managed retreat within the estuary and the associated creation of saltmarsh.

(2) The role of subtidal species and habitats in providing waste remediation, as a means of addressing poor water quality.

(3) Changes in the provision of benthic nursery habitat (as a supporting service for fisheries provision), as a result of more active management of trawling, dredging and aggregate extraction.

(4) Changes in the provision of cultural ES, particularly recreational bird watching, as a result of the regulation of coastal recreational uses that create disturbances that affect birds.

(5) Changes in the provision of cultural ES, particularly visual amenity, due to the Atlantic Array offshore wind farm.

Stakeholder meetings were held to determine the relative importance of different ways that MESA information might be used in decision-making and stakeholder processes (Table 1). The design and comparison of management options were chosen as the most importance potential uses of MESA data.
Stage 2

Two approaches were used to implement Stage 2 of the triage: a deliberative process involving experts (the NDBR Coordinator and the environmental economists who would be carrying out the MES assessment), and a web-based survey to determine the individual opinions of local stakeholders. Local stakeholders, identified through the NDBR Coordinator and the NDBR Marine Working Group, included members of the management partnership and individuals and groups representing local marine interests. The specific ES scores from each stakeholder were averaged to provide the final weighting for the stakeholder group as a whole. Further stakeholder meetings were convened to discuss the results of the scorings and to ensure agreement on the approach.

Both the expert deliberation and the stakeholder survey gave the highest overall scores to an assessment of the fish/shellfish nursery habitat provided by benthic substrates (Table 3). The high score for actions that would better manage nursery habitats was due to the combination of a perceived vulnerability of the demersal fishery to changes in benthic habitat and to the local importance of the fishery. This issue also scored highly due to the likelihood it could be influenced by local policy, because actions to better manage benthic habitats can directly affect the provision of this service and such management measures can be implemented by locally-based public agencies such as the Inshore Fisheries and Conservation Authority. The assessment of nursery habitats was given a moderate score for the influence of external factors on the value of the service, as the ability of the habitats to sustain the service can be affected by changes in the physical characteristics of the water 
column (such as temperature) or changes in the species present.

Changes in cultural services, specifically visual amenity, that could be affected by the Atlantic Array wind farm also scored highly. Loss of visual amenity is likely to result in a large change in value, as this benefit is very important to people particularly in light of the designation of the coastline as an Area of Outstanding Natural Beauty. The unlikely influence of external factors also contributed to the high score provided by the experts, as only manmade developments such as the offshore wind farm are likely to have a significant influence on that value. It remains unclear why stakeholders, on average, felt that external factors would have a large impact on the value of the seascape and hence gave a low score in this category. The score given to the visual amenity service in the policy category was only moderate. This was because there is a lack of local control over the policy decision: while a MES assessment might form a useful part of the NDBR management partnership's input into the consultation, the final decision would be made at a national level.

Changes in the provision of carbon storage as a result of managed retreat in the estuary scored moderately high, but the change in the value of the service was not expected to be large as only small areas would be affected by the proposed management action. The issues of recreational bird watching and of waste remediation had low scores, because, the change in value was again expected to be small. Also, external factors were expected to have a larger influence than local policies on recreation.

ES related to benthic habitats and the visual amenity effects of the offshore wind farm were given equal scores during the expert deliberation process, although the 2 policy issues had different scores in the individual categories. During a stakeholder meeting to discuss the survey results, it was decided that, in the NDBR context, the policy implications category should be weighted more highly than the external factors likely to affect the value. This was because those external factors affecting the fisheries nursery habitat are mostly long-term, gradual changes; their effect on management interventions proposed for the near future was likely to be small.

The triage helped stakeholders and managers identify the fish/shellfish nursery provided by benthic habitats as the ES for which an assessment would be most beneficial in policy decisions facing the NDBR. The management processes that would be informed by the results of a MESA include proposals for areas within the NDBR to become part of the national Marine Conservation Zones network, and local policy decisions that would strengthen voluntary fisheries agreements, both of which aim to protect benthic habitats by imposing restrictions on certain activities. It was noted that a MESA of fisheries nursery services provided by benthic habitats could also be used more broadly in assessing the implication of activities such as marine renewable energy, increased aggregate extraction or other developments likely to impact on these habitats.

\section{Stage 3}

The questions in Stage 3 were used by stakeholders and the environmental economists as points of departure to discuss the choice of methods and metrics for assessing the selected ecosystem services. Resources at the disposal of the NDBR were insufficient to conduct primary, empirical data collection or monetary valuation. Thus, the MESA had to be restricted to considering habitats at a broad scale (to match the available data) and to providing qualitative assessments of the delivery of services, based primarily on information from the literature. The stakeholders were satisfied with the proposed approach, and concluded that meaningful information could be provided by such an assessment, particularly in fulfillment of the objectives of the MESA to improve knowledge and raise awareness. It was also felt that a simple MESA would be adequate for comparative purposes, as it provided a consistent treatment of different management scenarios.

\section{Iroise Marine Natural Park (PNMI)}

The PNMI, created in 2007 off the coast of Finistère, France, covers $3500 \mathrm{~km}^{2}$ and is notable for its natural marine ecosystems that are home to large numbers of species of seaweed and macroalgae, marine mammals and birds, traditional fishing activities and an extremely varied cultural heritage. In addition to its Marine Natural Park status, as defined by the French Law adopted on 24 April 2006 , this region of the Iroise Sea is a marine protected area under the Oslo-Paris Convention (OSPAR) and a large part of its perimeter is listed under the European Habitats and Birds directives (Natura 2000 network) and as a UNESCO biosphere reserve since 1989 (PNMI 2010). 


\section{Stage 1}

According to the French Environmental Code, a Marine Natural Park must contribute to the knowledge of maritime patrimony, the conservation of the marine ecosystems and the sustainable development of human activities in the sea. In line with these general goals, the PNMI Management Plan for 2010-2015 defines a series of 10 specific objectives in relation to knowledge of marine ecosystems, conservation of habitats, pollution mitigation, material extraction activities, fisheries, kelp exploitation, tourism and recreational activities, and the preservation of architectural, maritime, archeological and traditional heritage.

Kelp harvesting already occurs in the PNMI and the sustainable exploitation of kelp is a pressing management issue for the Park. As a result, the Park staff chose kelp management as the topic that could benefit most from a MESA. Harvested kelp is used for alginate production, but left in situ these kelp ecosystems also deliver many other services due to their biological productivity, biodiversity and contribution to the cultural heritage of the area (e.g. kelp has long been used as a traditional Breton food and a number of words in Breton exist to describe kelp). Thus, the ES approach is expected to provide new insights to the current management debate, which requires a better understanding of the trade-offs between the exploitation and conservation of kelp ecosystems in a context where the demand for kelp harvesting is increasing, at least for Laminaria hyperborea.

In the PNMI case study site, 3 objectives for a MESA of kelp habitats were identified: 2 decisive uses (to compare management options and to facilitate trade-offs), and an informative use (to improve knowledge). The most pressing policy issue for the Park concerns whether and how to regulate the increase in kelp harvesting, which is driven by an increasing demand from the agrifood industry. The scope of the MESA was thus delimited by the need for the PNMI to propose specific management measures for kelp forest in this area.

Meetings with park managers and staff were used to determine the relative importance of the uses that could be made of MESA data. As in the NDBR case, comparing management options was deemed a priority use.

\section{Stage 2}

Stage 2 was carried out using a consensus-based approach by a group of experts including 1 manager,
2 economists and 3 ecologists; 3 meetings were held with the final aim of selecting the main ES to be assessed.

The preliminary scoping identified the following ES and functions provided by kelp ecosystems in the Iroise Sea: 11 provisioning services, 10 regulation and maintenance services and 10 cultural services (see Table 4). The expert panel applied Stage 2 of the triage to these ecosystem services, scoring the answers to the 3 questions numerically and then using a numerical average of the questions to create a final score.

Six ES are expected to have high 'potential for the ES value to change' (Table 4). The increasing demand for kelp harvesting will be strongly influenced by the demand for alginate by the food industry, as well as other uses including crop fertilizer. The local demand for leisure will likely boost both recreational activities and ecotourism. In response to these potential changes, the PNMI is considering the creation of areas that would be closed to kelp harvesting. Each area would have different functions (biodiversity reserves, marine mammal refuges, and reference zones for scientific purposes). Seasonal rules for kelp harvesting may also be adopted by the park authorities. The efficiency of these management measures on ES delivery will depend on both the biological dynamics of kelp fields and the harvesting strategy dynamics of kelp fishermen. 'Influence of management' will affect mostly the harvesting of kelp, commercial abalone fisheries, the protection of biodiversity and habitat for abalones, the symbolic values associated with remarkable species, and ecotourism.

Two 'external factors of change' are particularly relevant in the Iroise Sea. (1) Climate change may result in a shift of sea temperature that could lead to a decline of one of the harvested species, Laminaria digitata (Raybaud et al. 2013). Changes in L. digitata are likely to cause a change in species composition of kelp forests and a decline of species closely related to $L$. digitata which could, in turn, lead to changes in the provision of ES in the Iroise Sea. (2) Strategies undertaken independently by the processing industry may also result in a relocation of the fishing fleet activities toward less controlled areas outside the PNMI.

Combining the results of the 3 questions, the expert panel concluded that a MESA would be best applied for 5 ES: provisioning services from kelp for the food industry, other industries and the abalone commercial fisheries, the regulating services linked to the maintenance of habitat for abalone, and the cultural services for ecotourism. A further 6 services 
Table 4. Scores assigned for ecosystem services (ES) affected by kelp harvest in the Iroise Marine Natural Park (PNMI). Scores assessed the usefulness of carrying out an assessment and were assigned as follows: $3=$ high, $2=$ moderate and $1=$ low usefulness. See Table 2 for criteria for scoring

\begin{tabular}{|c|c|c|c|c|}
\hline $\begin{array}{l}\text { ES Category } \\
\text { Specific ecosystem functions and services }\end{array}$ & $\begin{array}{l}\text { Potential } \\
\text { for } \\
\text { ES value } \\
\text { to change }\end{array}$ & $\begin{array}{c}\text { Influence } \\
\text { of manage- } \\
\text { ment }\end{array}$ & $\begin{array}{l}\text { Other } \\
\text { factors }\end{array}$ & $\begin{array}{l}\text { Final } \\
\text { score }\end{array}$ \\
\hline \multicolumn{5}{|l|}{ Provisioning services } \\
\hline \multicolumn{5}{|l|}{ Food provision } \\
\hline Abalone commercial fisheries & 2 & 3 & 2 & 2.3 \\
\hline Commercial fin fisheries (pollock and seabass) & 1 & 2 & 3 & 2.0 \\
\hline Lobster commercial fisheries (fish pots) & 1 & 1 & 3 & 1.7 \\
\hline Kelp used in alginates for food industry & 3 & 3 & 1 & 2.3 \\
\hline Aquaculture & & & & \\
\hline \multicolumn{5}{|l|}{ Biotic materials and biofuels } \\
\hline Crop fertilizer and pest management & 3 & 2 & 1 & 2.0 \\
\hline Kelp used in alginates for other industries & 3 & 3 & 1 & 2.3 \\
\hline Medicinal uses (non alginate) & 2 & 1 & 3 & 2.0 \\
\hline Cosmetic uses (non alginate) & 2 & 1 & 3 & 2.0 \\
\hline Disservice: Bycatch (Saccorhiza polyschides) & 2 & 2 & 2 & 2.0 \\
\hline \multicolumn{5}{|l|}{ Maintenance and regulation services } \\
\hline \multicolumn{5}{|l|}{ Coastal protection } \\
\hline \multicolumn{5}{|l|}{ Ocean nourishment } \\
\hline Strong primary productivity & 2 & 2 & 1 & 1.7 \\
\hline \multicolumn{5}{|l|}{ Life-cycle maintenance } \\
\hline Improvement of kelp resilience & 2 & 2 & 2 & 2.0 \\
\hline Key habitats that support a strong biodiversity: & 2 & 3 & 1 & 2.0 \\
\hline for commercial fishes & 1 & 2 & 3 & 2.0 \\
\hline for abalone & 2 & 3 & 2 & 2.3 \\
\hline for European lobster & 1 & 1 & 3 & 1.7 \\
\hline for bottlenose dolphins & 2 & 2 & 2 & 2.0 \\
\hline for grey seals & 2 & 2 & 2 & 2.0 \\
\hline for seabirds & 2 & 2 & 2 & 2.0 \\
\hline \multicolumn{5}{|l|}{ Cultural services } \\
\hline \multicolumn{5}{|l|}{ Symbolic and aesthetic values } \\
\hline Traditional activity & 3 & 1 & 2 & 2.0 \\
\hline Charismatic seascape & 2 & 2 & 1 & 1.7 \\
\hline Charismatic species & 2 & 3 & 1 & 2.0 \\
\hline \multicolumn{5}{|l|}{ Recreation and tourism } \\
\hline Recreational fishing (shellfish, crustaceans and finfish) & 3 & 2 & 1 & 2.0 \\
\hline Boating & 1 & 1 & 2 & 1.3 \\
\hline Kayaking & 1 & 1 & 2 & 1.3 \\
\hline Sealife watching (ecotourism) & 2 & 3 & 2 & 2.3 \\
\hline \multicolumn{5}{|l|}{ Cognitive effects } \\
\hline Material for research & 3 & 2 & 1 & 2.0 \\
\hline Material for arts & 1 & 1 & 3 & 1.7 \\
\hline School excursion / awareness campaign & 2 & 1 & 3 & 2.0 \\
\hline
\end{tabular}

with the second best score were also explicitly targeted by the PNMI Management Plan, and it was decided that these should also be assessed if sufficient time, resources and data were available. These were: commercial finfisheries, supporting services provided by kelp for biodiversity, commercial fish habitats, foraging bottlenose dolphins and seabirds (that in turn provide recreational and existence val- 
ues), and the cultural values associated with other unique and charismatic species. Other services that were initially considered, for instance water quality regulation, climate regulation and coastal protection, either scored low or could not be scientifically linked to expected changes in ecosystem conditions.

\section{Stage 3}

Based on discussions regarding the 3 questions of Stage 3, the expert panel chose the following metrics to measure: the biomass and spatial distribution of kelp, the size of the habitats available for protected or charismatic species, kelp and fisheries harvest, the economic indicators associated with kelp and fish harvest (added value, employment and contribution to traditional activities), and recreational activities (visitor numbers, especially changes in visitor numbers caused by new rules). Considering the aim of the ESA in this site and the indicators that were determined to be meaningful, a system dynamic model for simulating the impacts of various fisheries management options on relevant ES will be used. A biological model of algae production and a spatial model of kelp distribution are already available. Both models will serve as the basis for the ecological component of a social-ecological dynamic model, which should be completed with modules simulating uses (kelp and fish harvesting) and governance (access rules).

\section{DISCUSSION}

The triage approach proved useful as a framework for structuring clear and transparent discussions that helped teams in both the UK and France focus their MESAs. A variety of approaches for the implementation of the triage were applied. During the implementation of Stage 2, the case study in North Devon compared the advantages of a survey and a more deliberative process. The latter was considered preferable as MES experts and stakeholders have different and complementary expertise: The experts have a more thorough understanding of MES quantification methods and the potential for service delivery and value to change, while the stakeholders possess stronger local knowledge on policy options and what is important locally. A survey alone provides no opportunity to discuss the issues, and the outcome may vary depending on how the data are processed, decreasing the transparency and objectivity of the approach. In both case studies, the triage lent itself to a numerical approach for the choice of ES to focus on (Stage 2) while the triage questions were used primarily for guiding discussions in Stages 1 and 3.

For both the NDBR and the PNMI cases, the triage approach helped experts and stakeholders to share their knowledge of both the functioning of marine ecosystems and also the limits of proposed management options. The systematic and transparent approach used to refine the types of ecosystem services to consider in policy scenario analysis helped to keep stakeholders confident in the process, because a wide array of ES was examined and considered in a transparent way.

Both case studies, as well as 4 other case studies included in the VALMER project, confirm the advantages of adopting a systematic process to focus MESAs. Such an approach can be used to narrow the range of policies or decisions that are likely to benefit from a MESA and to also identify which of many ES and changes should be quantified through a multidisciplinary scientific assessment. In both case studies, these early refinements set the stage for a final application of the triage approach to the choice of methods for assessment and metrics that will be used to quantify ES value and benefit.

The VALMER project launched into the triage process due to demand by the multidisciplinary team of experts, stakeholders and decision-makers. Initially, the VALMER team was unaware of the growing field of study known as 'structured decision-making' (SDM) (Gregory et al. 2012). In the present study, we refer to our approach here as SDM, but we concede that a more thorough review of the SDM field before we commenced our work would have provided additional guidance about how to engage stakeholders and experts. Indeed, even the application of the triage approach to the VALMER cases was an iterative, learning process. The questions and methods used further changed during the application of the triage to the full suite of sites examined by the VALMER Project. 1

The questions used in the triage SDM were intended to address certain concerns that were common among stakeholders at the sites. These questions are admittedly simplified and by no means

\footnotetext{
1 In the French and English contexts, we found that the word triage was considered neutral, but we recognise that in other contexts it may not be (O'Neill \& Nicholson-Cole 2009). We encourage the reader to consider the term as simply referring to a structured, transparent approach, such as structured decision-making (SDM).
} 
definitive, nor do they capture many other issues that may be relevant for marine planners and stakeholders. For instance, the questions used in the triage do not shed light on the importance of cumulative effects or the interactions of different policy actions or human factors. Similarly, the triage questions were chosen to inform local decision-making. One could easily imagine a local MESA might be undertaken to inform local stakeholders about the potential impacts of extra-local policies (e.g. EU directives) or global environmental changes. We encourage the reader to consider our initial attempt at structure decision making as evidence that such an approach is useful and feasible, but with the understanding that the questions that underpin such an approach will need to be improved and tailored for the needs of marine planners and stakeholders and the context in which they work and live.

Acknowledgements. The VALMER project was selected under the European cross-border cooperation programme INTERREG IV A France (Channel) - England, co-funded by the European Regional Development Fund. The participation of L.P. was supported by the 'Laboratoire d'Excellence' LabexMER (ANR-10-LABX-19) and co-funded by a grant from the French government under the program 'Investissements d'Avenir'.

\section{LITERATURE CITED}

Bagstad KJ, Semmens DJ, Waage S, Winthrop R (2013) A comparative assessment of decision-support tools for ecosystem services quantification and valuation. Ecosystem Services 5:27-39

Börger T, Beaumont N, Pendleton L, Boyle K, and others (2014) Incorporating ecosystem services in marine planning: the role of valuation. Mar Policy 46:161-170

Egoh B, Rouget M, Reyers B, Knight AT, Cowling RM, van Jaarsveld AS, Welz A (2007) Integrating ecosystem services into conservation assessments: a review. Ecol Econ 63:714-721

Gregory R, Failing L, Harstone M, Long G, McDaniels T, Ohlson D (2012) Structured decision making: a practical guide to environmental management choices. John

Submitted: March 6, 2014; Accepted: November 11, 2014
Wiley \& Sons, Chichester

Honey-Rosés J, Pendleton LH (2013) A demand driven research agenda for ecosystem services. Ecosyst Serv 5: 160-162

Laurans Y, Rankovic A, Billé R, Pirard R, Mermet L (2013) Use of ecosystem services economic valuation for decision making: questioning a literature blindspot. J Environ Manage 119:208-219

Lopes R, Videira N (2013) Valuing marine and coastal ecosystem services: an integrated participatory framework. Ocean Coast Manage 84:153-162

Marcone O, Mongruel R (2014) Looking beyond academic application of environmental valuation: what practical uses of economic valuation in decision-making processes? The case of marine environment. Amure Publications, Work Pap Ser D 37 2014. www.umramure. fr/electro_doc_amure/D_37_2014.pdf (accessed on 17 December 2014)

MEA (Millennium Ecosystem Assessment) (2005) Ecosystems and human well-being: a synthesis. MEA, Washington, DC

NDBR (North Devon's Biosphere Reserve) (2008) Our strategy for sustainable development 2008-2012. North Devon Coast and Countryside Service, Bideford

NDBR (North Devon's Biosphere Reserve) (2011) Revised 2011-2013 action plan. www.northdevonbiosphere.org. uk/annual-reports-and-action-plan.html (accessed on 17 December 2014)

O'Neill S, Nicholson-Cole S (2009) Fear won't do it. Promoting positive engagement with climate change through visual and iconic representations. Sci Commun 30:355-379

PNMI (Parc Naturel Marin d'Iroise) (2010) Management plan of the Iroise Marine Natural Park. French with English summary. Parc Naturel Marin d'Iroise, Le Conquet

Ruckelshaus M, McKenzie E, Tallis H, Guerry A and others (in press) Notes from the field: lessons learned from using ecosystem service approaches to inform real-world decisions. Ecol Econ. doi:10.1016/j.ecolecon.2013.07.009

Tallis H, Lester SE, Ruckelshaus M, Plummer M and others (2012) New metrics for managing and sustaining the ocean's bounty. Mar Policy 36:303-306

TEEB (The Economics of Ecosystems and Biodiversity) (2010) The Economics of Ecosystems and Biodiversity: mainstreaming the economics of nature: a synthesis of the approach, conclusions and recommendations of TEEB. www.teebweb.org/publication/mainstreamingthe-economics-of-nature-a-synthesis-of-the-approachconclusions-and-recommendations-of-teeb/ (accessed on 17 December 2014)

Proofs received from author(s): February 27, 2015 